Article

\title{
Comprehensive Research on Remote Sensing Monitoring of Grassland Degradation: A Case Study in the Three-River Source Region, China
}

\author{
Ying Zhang ${ }^{1,2}$, Chaobin Zhang ${ }^{1}$, Zhaoqi Wang ${ }^{3}$, Ru An ${ }^{4}$ and Jianlong Li ${ }^{1, *}$ \\ 1 Department of Ecology, School of Life Science, Nanjing University, Nanjing 210046, China; \\ zhang_ying@fudan.edu.cn (Y.Z.); chaobinzhang@smail.nju.edu.cn (C.Z.) \\ 2 School of Life Sciences, Fudan University, Shanghai 200438, China \\ 3 College of Urban and Environmental Sciences, Peking University, Beijing 100871, China; wzqi@pku.edu.cn \\ 4 School of Earth Science and Engineering, Hohai University, Nanjing 210098, China; anrunj@163.com \\ * Correspondence: jlli2008@nju.edu.cn
}

Received: 18 February 2019; Accepted: 22 March 2019; Published: 27 March 2019

\begin{abstract}
In this study, we proposed climate use efficiency (CUE), a new index in monitoring grassland ecosystem function, to mitigate the disturbance of climate fluctuation. A comprehensive evaluation index (EI), combining with actual vegetation net primary productivity (NPP), CUE, vegetation coverage, and surface bareness, was constructed for the dynamic remote sensing monitoring of grassland degradation/restoration on a regional scale. By using this index, the grassland degradation/restoration in the Three-River Source Region (TRSR) was quantitatively evaluated during 2001-2016, which has been an important ecological barrier area in China. Results showed the following: During the study period, the grassland of Yellow River source (SRYe) had high vegetation coverage, NPP, CUE, and low bareness, whereas Yangtze River source (SRYa) had low vegetation coverage, NPP, CUE, and high bareness. The vegetation coverage and CUE of the grassland showed upward trends, with annual change rates of $0.75 \%$ and $0.45 \%$ year ${ }^{-1}$. The surface bareness and NPP showed downward trends, with annual change rates of $-0.37 \%$ year $^{-1}$ and $-0.24 \mathrm{~g} \mathrm{C} \mathrm{m}^{-2} \mathrm{yr}^{-2}$, respectively. Assessment of EI revealed that $67.18 \%$ of the grassland of TRSR showed a recovery trend during the study period. The overall restoration of the SRYe was the best, followed by SRYa. However, the status of Lancang River source (SRLa) was poor.
\end{abstract}

Keywords: grassland degradation; comprehensive remote sensing monitoring index; climate use efficiency (CUE); surface bareness; Three-River Source Region

\section{Introduction}

The area of grassland degradation reached $14 \times 10^{6} \mathrm{~km}^{2}$ in 2010, accounting for nearly $49.3 \%$ of the world's grassland area [1]. Grassland degradation is an urgent ecological and economic problem worldwide, particularly in China [2]. Natural grassland occupies $41 \%$ of the total land area of China, which is 1.95 times higher than woodland and 2.62 times higher than cultivated land. Natural grassland is an important material base of animal husbandry and also a main ecological barrier in northern China [3]. To date, $90 \%$ of the natural grassland in China has a different degree of degeneration, increasing at a speed of $6700 \mathrm{~km}^{2}$ annually [4]. Improved methods for monitoring land degradation across spatial and temporal scales will be crucial for understanding and addressing the risk of grassland degradation.

In the past decades, the technologies of remote sensing have evolved dramatically to include a suite of sensors at a wide range of image scale. So far, remote sensing has played an unprecedented role in land degeneration mapping, assessment, and monitoring at multiple spatial and temporal 
scales [5], offering broadly automated and repeatable methods for indicators of vegetation condition [6]. Grassland vegetation index, such as net primary productivity (NPP), vegetation coverage, or biomass is the direct manifestation of grassland degeneration [7]. Many previous studies have calculated vegetation related index and analyzed spatial-temporal dynamics successfully over the given observation period $[5,8]$. Some studies have attempted to monitor grassland degradation through NPP, normalized index (NDVI), enhanced vegetation index (EVI), vegetation coverage, surface temperature, land-cover dynamic, and other indicators [6,9-13].

However, there are difficulties in remote sensing evaluation and monitoring of grassland degradation. Some researchers are limited by large-scale monitoring and time-consuming manual interpretation of satellite image based on field survey. The flaws of vegetation indexes for monitoring could lead to some inaccurate assessments such as singular classification index, inconsistency of diagnostic criteria, and misuse of remote sensing data [14,15]. In particular, inter-annual grass growth fluctuates with climatic condition when monitoring temporal dynamic change; therefore, it is hard to distinguish grassland degradation from the influence of climate. It leads to overestimating of the severity of degradation in a poor harvest year and underestimating in bumper harvest year. In view of this problem, some studies have attempted to diagnose degradation by using rain-use efficiency (RUE) [16-18]. However, these indexes only focus on the water variation in suitable arid areas. Besides, singular monitoring indicators have certain degree of defects, deviation or uncertainties. Researchers often need to identify the most appropriate one for specific applications [6]. For that reason, the comprehensive use of multiple indicators can compensate for single index defects, improving the monitoring and evaluation accuracy [19].

In this study, we attempted to construct a comprehensive evaluation method for the dynamic remote sensing monitoring of grassland degradation/restoration on a medium scale. Meanwhile, we proposed climate use efficiency (CUE) as a new index in monitoring grassland ecosystem function to mitigate the disturbance of climate fluctuation. We then quantitatively diagnosed grassland degradation/restoration in the TRSR during 2001-2016. This study could serve as a theoretical reference for the treatment and rational utilization of grassland resources, offering demonstration and reference for similar research.

\section{Study Area and Materials}

\subsection{Study Area}

The study area is the TRSR (see Figure 1), which located in the hinterland of the Tibetan Plateau $\left(31^{\circ} 39^{\prime \prime}-36^{\circ} 12^{\prime \prime} \mathrm{N}, 89^{\circ} 45^{\prime \prime}-102^{\circ} 23^{\prime \prime} \mathrm{E}\right)$, known as the "Water Tower of China", the headstream of three major rivers in East Asia (i.e., the Yangtze River, the Yellow River and the Lancang River). Around $40 \%$ of the world's population depends on, or is influenced by, these rivers [20]. The TRSR covers an area of $350,000 \mathrm{~km}^{2}$, in which the area of SRYa, SRYe, SRLa accounts for $43.2 \%, 39 \%$, and $17.8 \%$, respectively [21]. The TRSR is mainly constituted of mountainous landform with the altitude of $3335-6564 \mathrm{~m}$. The climate is typical high-altitude plateau monsoon type, with annual mean temperature from $-5.38{ }^{\circ} \mathrm{C}$ to $4.14{ }^{\circ} \mathrm{C}$ and annual precipitation from $262.2 \mathrm{~mm}$ to $772.8 \mathrm{~mm}$ [22]. The grassland ecosystem is primary in the TRSR region, which accounts for $65.37 \%$ of the total area. The population is about 568,000 and most of the residents are nomadic Tibetan [21]. Because of rigorous climate and topography, grassland ecosystems in this region are fragile and consequently prone to damage and degeneration [22]. Over the past decades, grassland degradation in the TRHR has attracted much attention. The lives of residents are threatened by a deteriorating regional ecosystem and declining water conservation function. 


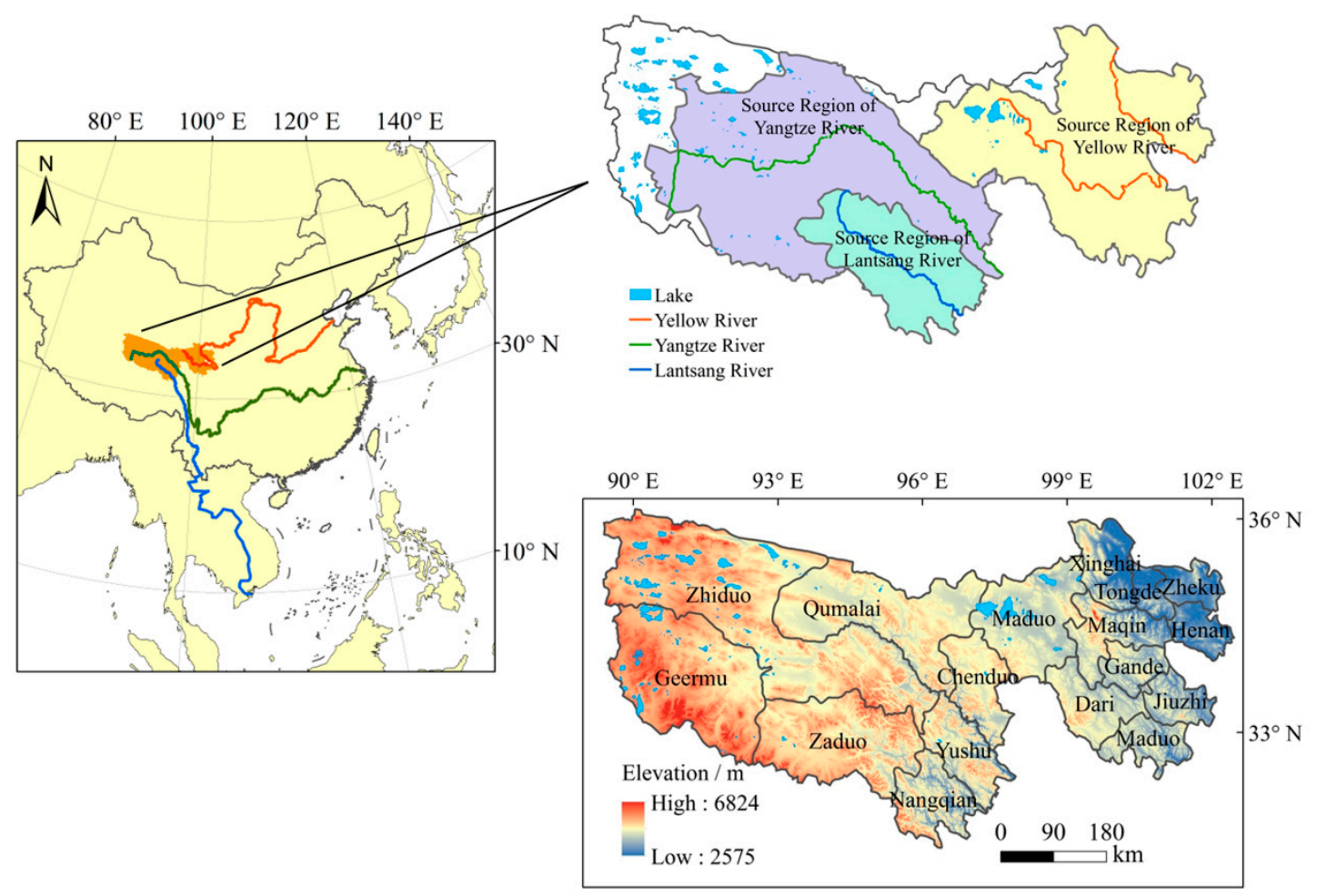

Figure 1. The map of location, administrative division, elevation and sub-regions in TRSR.

\subsection{Data Collection and Processing}

Moderate Resolution Imaging Spectroradiometer (MODIS) Monthly-L3 data products were adopted in this study. NDVI (Normalized Difference Vegetation Index) was directly extracted from MOD13A3. The red and thermal infrared bands to calculate surface bareness were extracted from MOD13A2 and MOD11A2, respectively. Soil temperature data were also from MOD11A2. All of the MODIS data were downloaded from https: / wist.echo.nasa.gov/api/ at $1 \mathrm{~km}$ space resolution and time span 2001-2016 with each year growth season (May-September). MODIS Reprojection Tools (MRT) was applied to mosaic and resampling of the images. Then, the maximum value composite (MVC) method was used to obtain monthly data.

Climate data included monthly average temperature, precipitation, and solar total radiation data in 50 standard meteorological sites provided by the China Meteorological Science Data Service Center (http:/ / cdc.cma.gov.cn) from 2001 to 2016 in the TRSR and surrounding areas. Through the specialized climate data space interpolation program ANUSPLIN (version 4.3) [23], interpolation processing obtained a weather raster data that is consistent with the NDVI data pixel size and geographical projection. Soil texture data is extracted from Harmonized World Soil Database (version 1.1) [24].

\section{Methods}

\subsection{The Calculations of Actual and Potential NPP}

The Carnegie-Ames-Stanford Approach (CASA) model, a light energy utilization process-based model, was applied to compute the actual NPP in the study. The CASA model is driven by remote sensing, meteorological data, and vegetation types. It has been calibrated by more than 1900 measured sites around the world [25] and also widely used in grassland productivity research. The specific calculation method and parameter setting were based on previous studies [26-28]. In the CASA model, the formula of NPP calculation is showed compactly as follows:

$$
N P P=F P A R \times A P A R \times \varepsilon,
$$


where FPAR is Fraction of Photosynthetically Active Radiation intercepted by green vegetation, APAR is vegetation absorbed photosynthetically active radiation, $\varepsilon$ is light use efficiency, which is restricted by temperature and precipitation. [29]

To ensure the contrast of the actual NPP with the potential NPP (that is, the NPP was only considered for climatic conditions), the calculation of the climate productivity model with the potential NPP is the same frame as CASA, except for the FPAR calculation. The differences of both are as follows: in the CASA model, the FPAR is estimated by NDVI:

$$
F P A R_{N D V I}=\frac{N D V I-N D V I_{i, \min }}{N D V I_{i, \max }-N D V I_{i, \text { min }}} \times\left(F P A R_{\text {max }}-F P A R_{\text {min }}\right)+F P A R_{\text {min }}
$$

where NDVI represents the NDVI value in a month; $N D V I_{i, \text { min }}$ and $N D V I_{i, \max }$ represent the maximum and minimum NDVI values of a certain vegetation cover type, respectively; FPAR $R_{\max }$ and FPAR $R_{\min }$ are 0.95 and 0.001 , respectively. Their values are independent of the vegetation cover type.

In the potential NPP model, FPAR were estimated with a Beer-Lambert law, as follows:

$$
F P A R_{\text {clim }}=1-e^{-k \times L A I},
$$

where $k$ is the light extinction coefficient. We take a constant value of 0.5 , typical for herbaceous vegetation [30]; LAI (Leaf Area Index) indicates leaf area index $\left(\mathrm{m}^{2} \mathrm{~m}^{-2}\right)$.

$$
L A I=L A I_{\min }+f_{s w} \times f s t \times\left(L A I_{\max }-L A I_{\min }\right)
$$

where $L A I_{\min }$ and $L A I_{\max }$ represent the minimum and maximum value of the leaf area index, respectively. $f_{s} w$ and $f_{s t}$ represent the limits of soil moisture and soil temperature on vegetation growth, respectively [24]. The calculations are as follows:

$$
f_{s t}=\min \left(1, \max \left(0,1-0.0016 \times(298-L S T)^{2}\right)\right)
$$

where $L S T$ is land surface temperature indicated soil temperature; $W_{\max }$ indicates the maximum soil moisture content that is soil texture dependent empirical coefficient:

$$
\begin{gathered}
f s w=\min \left(1, \max \left(0, \frac{\frac{W_{\text {soil }}}{W_{\max }}}{W_{\text {crit }}}\right)\right) \\
W_{\max }=0.332-7.251 \times 10^{-2} \text { sand }+0.1276 \log _{10} \text { clay }+0.2552
\end{gathered}
$$

$W_{\text {crit }}$ is constant at 0.25 , showing that the fractional water content reflecting the permanent wilting point; $W_{\text {soil }}$ indicates the soil water content, which was potential to accumulate soil moisture over several months as a state variable [31];

$$
\begin{gathered}
W_{\text {soil }(t)}=W_{\text {soil }(t-1)}+\left(\operatorname{Prcp}_{t}-E p_{t}\right) \times R D R \text { if } \operatorname{Prcp}_{t}<E p_{t} \\
W_{\text {soil }(t)}=W_{\text {soil }(t-1)}+\left(\operatorname{Prcp}_{t}-E p_{t}\right) \text { if } \operatorname{Prcp} p_{t} \geq E p_{t}
\end{gathered}
$$

where $\operatorname{Prcp} p_{t}$ is precipitation at month $t, E p_{t}$ is potential evapotranspiration at month $t$, RDR is relative drying rate scalar for potential water extraction as a function of soil moisture. If month average air temperature is below $0{ }^{\circ} \mathrm{C}, \operatorname{Prcp} p_{t}$ and $E p_{t}$ are defined as 0, which means that there is no water exchange between soil and atmosphere, and all precipitation accumulates as snow, which is added to Prcp in the first month of air temperature being above $0^{\circ} \mathrm{C}$. Ep is calculated using the same method as CASA. RDR is calculated as follows:

$$
R D R=\frac{1+a}{1+a \theta^{b}}
$$


where $a$ and $b$ are empirical content that relate to soil texture and $\theta$ is the soil water content of the previous month [31]:

$$
\begin{gathered}
a=e^{-4.396-7.15 \text { clay }-4.88 \text { sand }^{2}-0.4285 \text { sand }^{2}} \\
b=-3.14-22.2 \text { clay }^{2}-34.84 \text { sand }^{2} \text { clay }
\end{gathered}
$$

where clay and sand indicate clay and sand percentage (actual decimal value) of soil texture, respectively.

\subsection{Calculation of Vegetation Coverage}

The dimidiate pixel model, regarded as the simplest model of the linear spectral mixture analysis method to extract vegetation coverage, was applied to calculate grassland vegetation coverage. A highly significant correlation was observed between NDVI and vegetation coverage; hence, the vegetation coverage could be extracted directly from NDVI [32]. The expression formula is as follows:

$$
C_{i}=\frac{N D V I-N D V I_{\min }}{N D V I_{\max }-N D V I_{\min }}
$$

where $C_{i}$ is the vegetation coverage; $N D V I_{\max }$ and $N D V I_{\min }$ represent the maximum and minimum NDVI values of the study area, respectively. In this study, $N D V I_{\max }$ and $N D V I_{\min }$ are respectively defined by $95 \%$ and $5 \%$ quantile NDVI pixels in the growth season of TRSR (May September), which eliminates extreme pixel values (similarly hereinafter).

\subsection{Calculation of Surface Bareness}

Wang et al. [33] presented an imperviousness index (Normalized Difference Imperviousness Index, NDII) associated with surface visible red reflectivity and thermal infrared radiation. They further established the surface bareness index on the basis of NDII [34]. Although bareness is correlated with the concept of vegetation coverage, it is not a complementary set of coverage but an index containing surface reflectance and temperature, attributed to evaluation of urban ecological environments by remote sensing. Vegetation evapotranspiration could conspicuously reduce surface temperature compared to exposed soil surface under direct sunshine in growing season. These differences could be presented on image pixel values of grassland ecosystems [35-37]. Based on the above theoretical basis and practical research, this study introduces the surface bareness index to the remote sensing evaluation system of grassland ecological degradation. The calculation method of NDII is as follows:

$$
I_{N D I I}=\frac{\lambda_{r}-\lambda_{t}}{\lambda_{r}+\lambda_{t}}
$$

where $I_{\mathrm{NDII}}$ is the NDII value; $\lambda_{\mathrm{r}}$ and $\lambda_{\mathrm{t}}$ are the red band and thermal infrared band of the remote sensing image, respectively. Bareness index $F_{b}$ calculated based on $I_{N D I I}$ :

$$
F_{b}=\frac{I_{\text {NDII }}-I_{\text {NDIImin }}}{I_{\text {NDIImax }}-I_{\text {NDIImin }}}
$$

where $I_{\text {NDIImax }}$ and $I_{\text {NDIImin }}$ represent $95 \%$ and $5 \%$ quantile of all image pixels values of the study area in the lushest vegetation month (July), respectively.

\subsection{Calculation of Climate Utilization}

The inter-annual variability of climatic condition causes "harvest" and "less harvest years" of vegetation growth, which could easily interfere with the judgment of land degradation/restoration. RUE, the ratio of NPP to the corresponding precipitation, has been used to solve this problem $[21,38,39]$. Therefore, it can exclude the effects of inter-annual variability of precipitation on the diagnosis of grassland degradation. Though RUE is well applied in arid and semiarid, some studies have revealed that the effect of precipitation on the TRSR vegetation is significantly less than that of radiation and 
temperature $[27,40]$. Thus, considering the effects of radiation and temperature, this study presents a new degradation-monitoring index for climate utilization efficiency (CUE):

$$
C U E=\frac{N P P_{a}}{N P P_{p}}
$$

where $N P P_{\mathrm{a}}$ and $N P P_{\mathrm{p}}$ are the actual and potential NPP for the current year, respectively. CUE indicates the utilization efficiency of the main climatic factors, including light, temperature, and water in grassland ecosystems.

\subsection{Grassland Degradation/Restoration Classification and Grading Standard Construction}

In order to use the remote sensing information efficiently, a comprehensive evaluation index $(E I)$ for the monitoring of grassland degradation was established with four indexes: actual NPP, CUE, vegetation coverage, and surface bareness. Among them, NPP is a comprehensive indicator to analyze grassland degradation $[1,13,41]$, but yearly NPP obviously fluctuates with current weather conditions. Therefore, it is hard to separate degradation tendency from regular weather fluctuation. CUE can eliminate the influence of weather fluctuation effect on grassland degradation monitoring. Vegetation coverage and surface bareness are visual indexes of grassland degradation. Four types of indexes were normalized firstly, and principal component analysis (PCA) was carried out. If the sum of the first several principal component reaches $80 \%$, these components are extracted as EI. The calculation method is:

$$
\begin{gathered}
E I_{\mathrm{j}}=\sum_{j=1}^{4} I_{j} \times a_{j} \\
E I=\frac{E I_{j}-E I_{\text {min }}}{E I_{\max }-E I_{\text {min }}}
\end{gathered}
$$

$I_{j}$ represents the respective contribution rates of vegetation coverage, surface bareness, NPP, and $C U E ; a_{j}$ is the corresponding values of their first principal component of the eigenvector. $E I_{\max }$ and $E I_{\min }$ represent $95 \%$ and $5 \%$ quantile of all pixels in the study area, respectively.

Temporal trends of the index values were examined by ordinary least square analysis [42], which is a generally reliable method. If the slope is positive, the grassland is restorable; otherwise, it is a degrading one.

\subsection{Model Verification}

NPP data converted from field measurement biomass are used for model validation. The biomass data measured 50 quadrate plots with $1 \mathrm{~km} \times 1 \mathrm{~km}$ in August 2012 in TRSR. Each quadrate was sampled 5 replicated with $1 \times 1 \mathrm{~m}$ square area. The vegetation coverage and aboveground biomass data were obtained. Carbon allocation ratio is 58.7:41.3 between the underground and aboveground parts according to a study about carbon flux of meadows in the Tibetan Plateau [43]; the measured NPP is obtained as:

$$
N P P_{\text {measure }}=D M_{A G} \times\left(1+\frac{41.3}{58.7}\right) \times 0.542
$$

where $D M_{A G}$ is the aboveground dry matter, 0.542 accounts for the carbon content rate of grass dry matter [26].

The simulated NPP, vegetation coverage, and surface bareness obtained good results from the measured data, respectively (Figure 2). A strong negative correlation was observed between the MODIS retrieved bareness and the measured vegetation coverage, indicating that the index can be contrasted with the vegetation coverage index and the feasibility of introducing the evaluation system. 
(a)

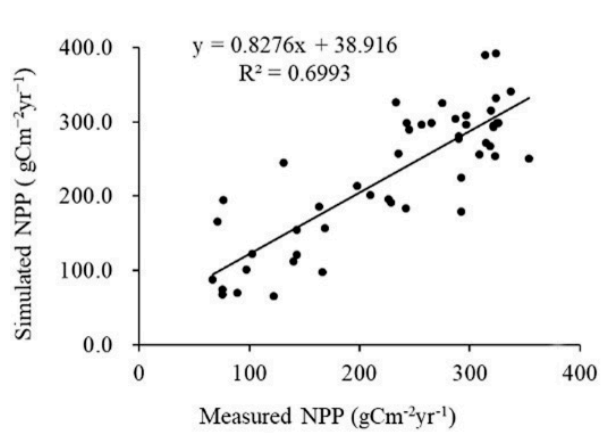

(b)

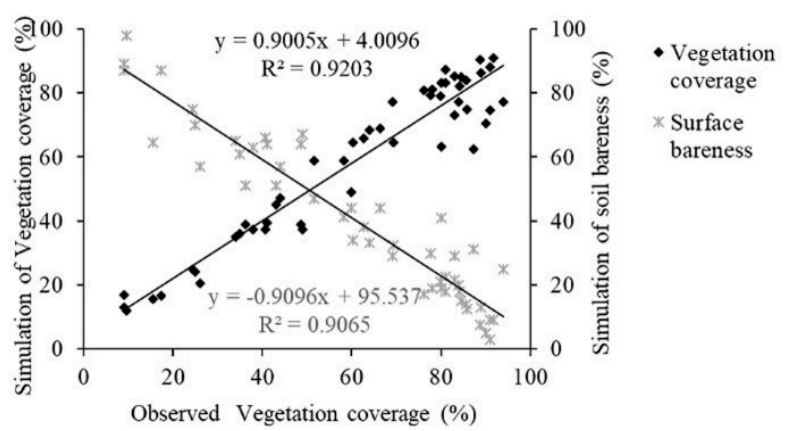

Figure 2. Comparison between simulated and measured data. (a) Actual NPP validation, (b) vegetation coverage and bareness index validation.

\section{Results}

\subsection{Spatiotemporal Pattern of Four Monitoring Indexes}

The spatial distribution characteristics of vegetation coverage (mean value of multi-year 2001-2016) are shown in Figure 3a. The annual average coverage was 50.40\%, showing decreasing distribution characteristics from southeast to northwest. The grassland coverage is high, mostly $75-90 \%$, in Zeku, Henan located to the east of $100^{\circ} \mathrm{E}$ and southern part of the TRSR, while coverage is low $(<25 \%)$ in Zaduo, Golmud located to the west of $94^{\circ} \mathrm{E}$.

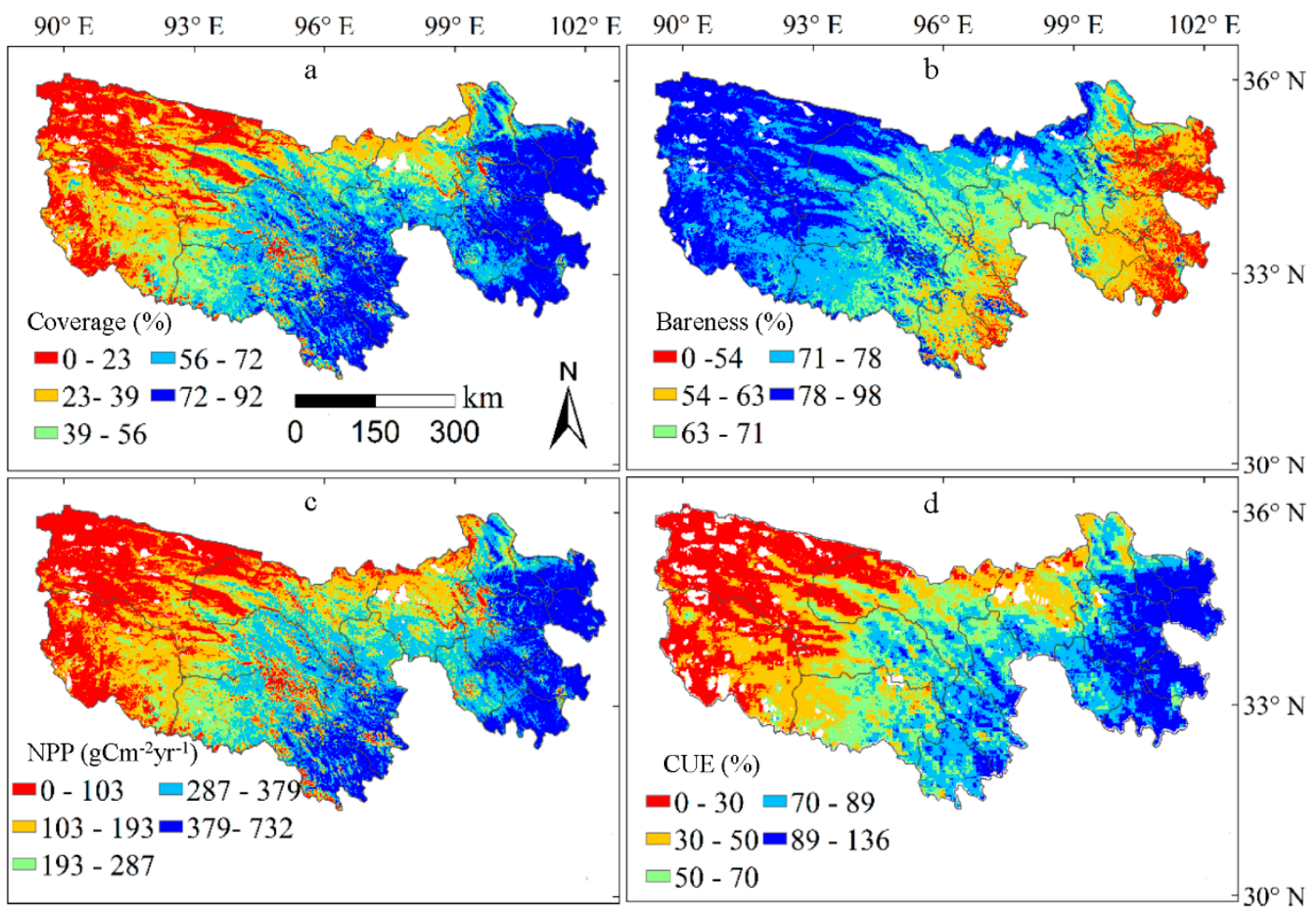

Figure 3. Spatial pattern of mean annual index in the TRSR over 2001-2016. (a) Vegetation coverage, (b) surface bareness, (c) NPP and (d) CUE.

The average surface bareness of the TRSR was $69.80 \%$, and spatial distribution was opposite to vegetation coverage. The bareness was high $(>75 \%)$ in Zaduo, Golmud, and Qumalai in the northern edge of the TRSR and other places west of $94^{\circ} \mathrm{E}$, while relatively low $(<50 \%)$ in Zeku and Henan County areas east of $100^{\circ} \mathrm{E}$, and Yushu in the southern part of the TRSR (Figure $3 \mathrm{~b}$ ). 
The average NPP of the TRSR was $198.74 \mathrm{~g} \mathrm{~m}^{-2}$ year $^{-1}$, showing decreasing distribution characteristics from southeast to northwest, which is consistent with the distribution of hydrothermal gradients in the TRSR (Figure 3c).

The spatial distribution of CUE showed obvious spatial heterogeneity (Figure 3d), presenting a spatial pattern high in the east and low in the west. The average of CUE was 57.69\% during 2001-2016. The region with high CUE value is located to the east of TRSR; the CUE value in Gande, and Henan County can reach more than $100 \%$. The region with low CUE (mainly $<25 \%$ ) is distributed in Zhiduo, Geermu County, and other places in the northwest.

We counted the different pixel values of vegetation coverage (Figure 4a), surface bareness (Figure 4b), NPP (Figure 4c), and CUE (Figure 4d) in the three river source areas: SRYe had high vegetation coverage, NPP, CUE, but low bareness. The average coverage, bareness, NPP, and CUE were $59.50 \%, 58.98 \%, 321.86 \mathrm{~g} \mathrm{~cm}^{-2}$ year $^{-1}$, and $84.01 \%$, respectively, whereas the corresponding distribution rates of their peak values were $60-85 \%, 50-80 \%, 290-500 \mathrm{~g} \mathrm{~cm}^{-2}$ year $^{-1}$, and $75-120 \%$. SRYa had low vegetation coverage, NPP, CUE and high bareness. The average coverage, bareness, NPP, and CUE were $40.17 \%, 74.75 \%, 196.97 \mathrm{~g} \mathrm{~cm}^{-2}$ year $^{-1}$, and $53.13 \%$, respectively, whereas the corresponding distribution rates of their peak values were $15-80 \%, 70-85 \%, 50-350 \mathrm{~g} \mathrm{~cm}^{-2}$ year $^{-1}$, and $15-100 \%$. SRLa had low vegetation coverage, NPP, CUE and high bareness. The average coverage, bareness, NPP, and CUE were $51.42 \%, 62.71 \%, 300.26 \mathrm{~g} \mathrm{~cm}^{-2}$ year $^{-1}$, and $80.94 \%$, respectively, whereas the corresponding distribution rates of their peak values were $60-72 \%, 60-75 \%, 350-450 \mathrm{~g} \mathrm{~cm}^{-2}$ year $^{-1}$, and $80-110 \%$.
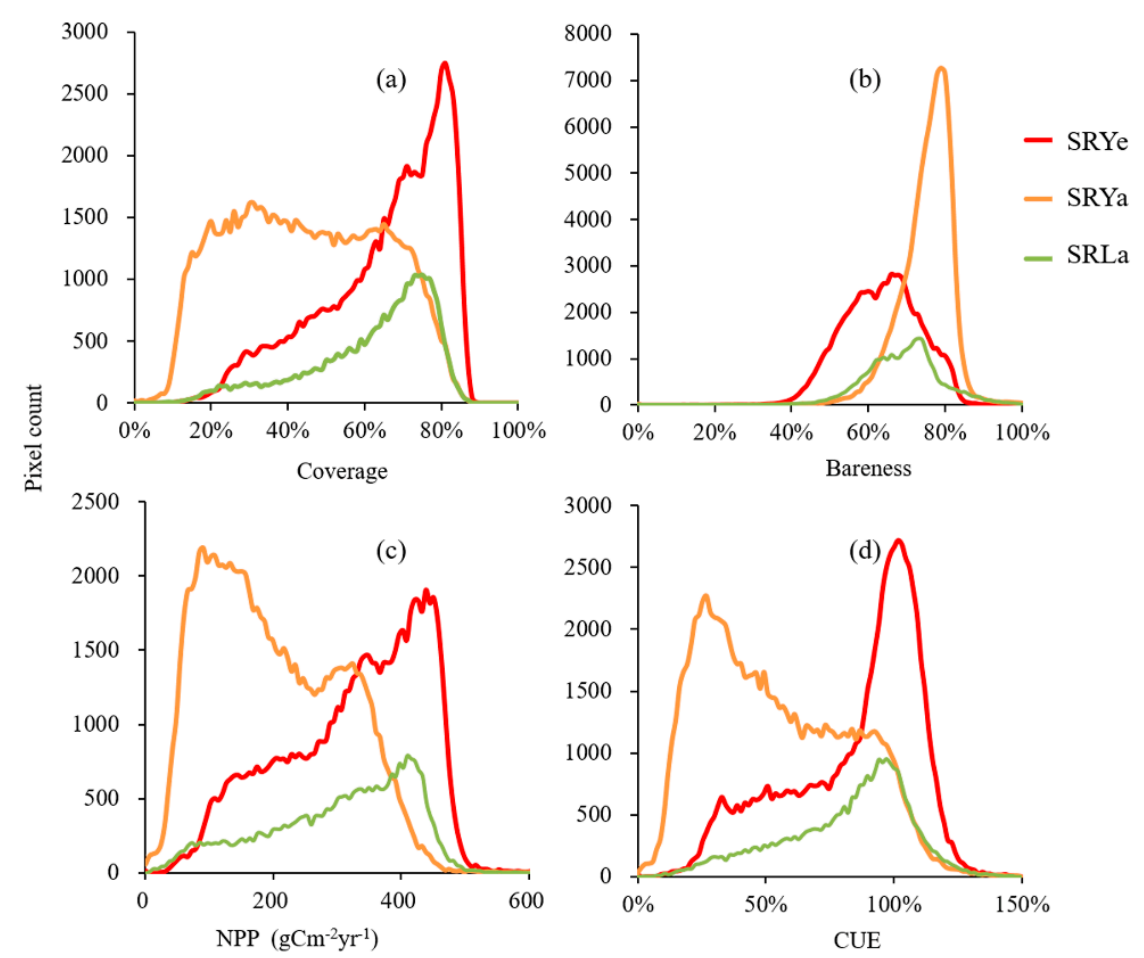

Figure 4. Statistics of pixel value count of mean annual index in each river source region over 2001-2016.

(a) Vegetation coverage, (b) surface bareness, (c) NPP and (d) CUE.

We analyzed the trend of four ecological indicators during 2001-2016, the spatial pattern of which is shown in Figure 5. In the whole of TRSR, the vegetation coverage has an overall upward trend (not shown in the fig) with average annual change rate of $0.53 \%$ year $^{-1}(p<0.01)$. The fastest growing regions were Maduo, Xinghai, and northern margin of Zeku County. The distribution of the coverage's rapidly decreasing region was dispersed (Figure 4a). The average value of surface bareness exhibited a downward trend at a rate of $-0.24 \%$ year $^{-1}(p<0.05)$. The area of rapid decrease 
was concentrated in SRYe, Gander, Long, south of Maduo County, and northeast of Yushu County, all located in the southern part of SRYe. The fast-growing area was in northwest Golmud, Xinghai and Maqin (Figure 5b). NPP has an insignificant downward trend $\left(-0.71 \mathrm{~g} \mathrm{Cm}^{-2} \mathrm{yr}^{-2}\right)(p>0.05)$. The area where NPP decreased rapidly was concentrated in the southern parts of SRYa and SRLa. The fast-growing area was located in Xinghai and Zeku County northern margin (Figure $5 c$ ). The CUE showed an insignificant upward rate of $0.45 \% \mathrm{yr}^{-1}(p>0.05)$. The fastest-growing regions were in Dari, Gande, Moduo, Chengduo County and the eastern parts of Qumalai and Zaduo County (Figure 5d).

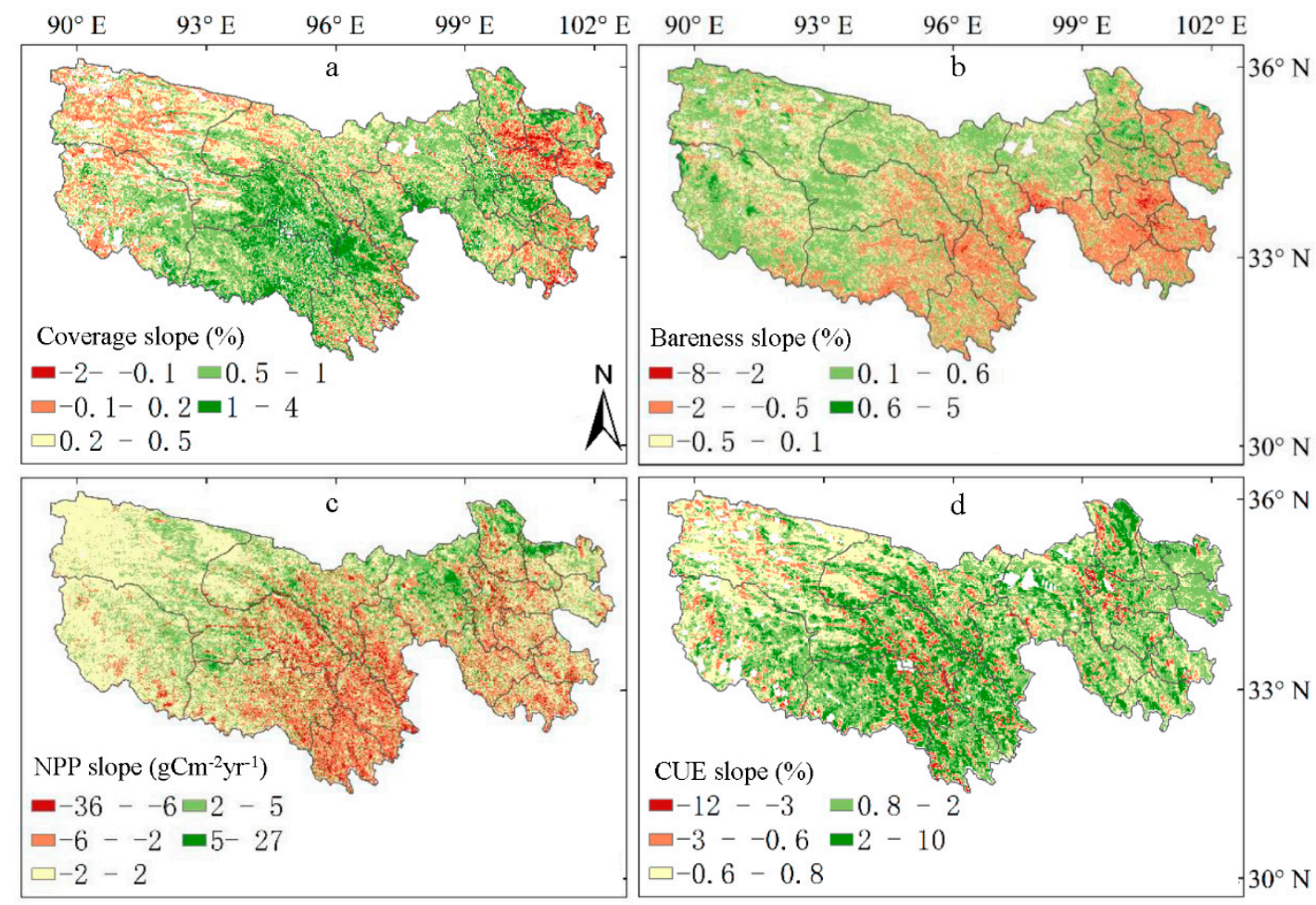

Figure 5. Inter-annual variation trends of four indexes in the TRSR grassland from 2001 to 2016. (a) Vegetation coverage, (b) surface bareness, (c) NPP and (d) CUE.

\subsection{Spatial Distribution Characteristics of Grassland Degradation Status}

As shown in Table 1, the cumulative contribution rate of the first principal component reached $93.12 \%$. Thus, the first principal component was extracted as EI. The corresponding values of the first principal component of the eigenvector are $0.45,0.25,0.70$, and 0.49 .

Table 1. Principal Component Analysis of four surface index.

\begin{tabular}{cccc}
\hline \multirow{2}{*}{ Principal Component } & \multicolumn{3}{c}{ ORIGINAL Eigenvalue } \\
\cline { 2 - 4 } & Eigenvalue & Percent of Eigenvalues & Accumulative of Eigenvalues \\
\hline 1 & 0.05 & 93.12 & 93.12 \\
2 & 0.00 & 3.31 & 96.43 \\
3 & 0.00 & 2.50 & 98.93 \\
4 & 0.00 & 1.07 & 100.00 \\
\hline
\end{tabular}

Figure 6a shows the trend of annual average EI in the TRSR grassland during 2001-2016. It showed an insignificant increasing trend $(p>0.05)$, and the rate of change was $0.39 \%$ year $^{-1}$. The lowest EI (0.45) was in 2003 and highest (0.55) in 2012. The whole TRSR was marked off as five types of change scenarios according to the significant levels of EI trend with $F$-test: extremely significant degradation (ESD, slope $<0, p<0.01$ ), significant degradation (SD, slope $<0,0.01<p<0.05$ ), insignificant variation 
(IV, $p>0.05$ ), significant restoration (SR, slope $>0,0.01<p<0.05$ ), and extremely significant restoration (ESR, slope $>0, p<0.01$ ). The distribution characteristics are shown in Figure 6b. The largest proportion was SR (64.14\%), which was widely distributed in the region, mainly in Zeku County, Dari County, Maduo County, Golmud East, and Zhiduo County South, followed by SD (29.91\%), mainly in the south and east of Maqin County, Yushu County, Nangqian County, and Zaduo County, the south-east of Chenduo County, and Zhiduo County. The ESR of grassland was 3.04\%, mainly distributed in the northern part of Maduo County and the northern part of Zhiduo County. The grassland of insignificant variation was $2.9 \%$, mainly distributed in the west of Geermu and Zhiduo County, whereas extremely significant degradation accounted for only $0.02 \%$.
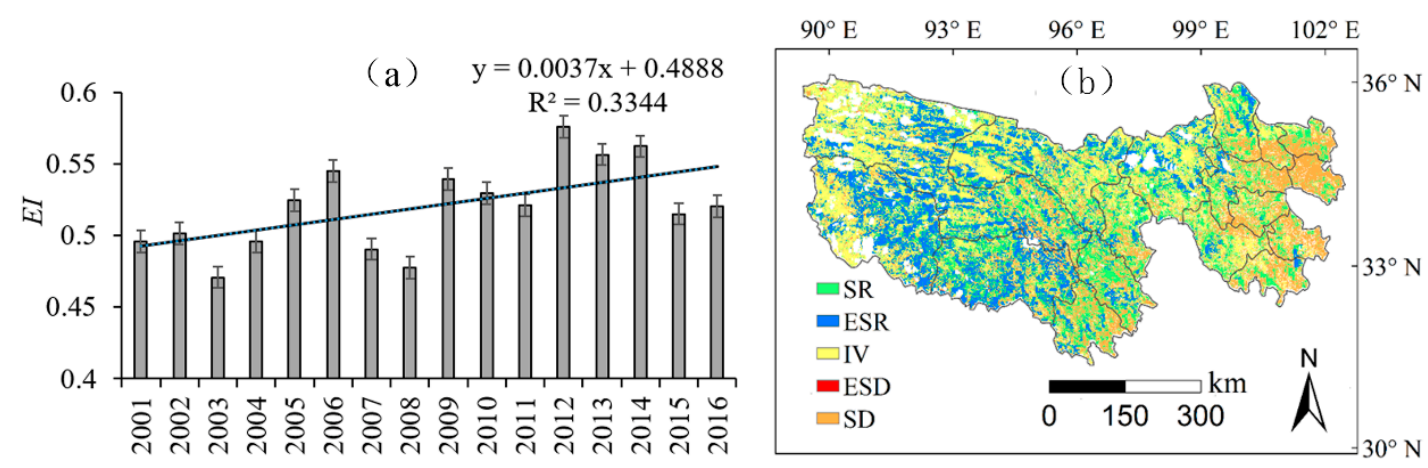

Figure 6. Dynamics of EI (a) and the grassland degradation/restoration situation (b) of Three-River-Source from 2001 to 2016. Note: SR indicates significant restoration, ESR indicates extreme significant restoration, IV indicates insignificant variation, ESD indicates extreme significant degradation, SD indicates significant degradation.

We further summarized the proportions of areas with different grassland degradation/restoration situations based on significant levels in the three sub-region (SRYa, SRYe and SRLa) (Figure 7). The restorable area was larger than the degenerating area in each sub-region. The grassland in SRYa of ESR, SR, IV, SD, ESD accounted for $29.50 \%, 10.10 \%, 48.69 \%, 4.92 \%$ and $6.78 \%$, respectively. The grassland in SRYe, ESR, SR, IV, SD, ESD accounted for $12.93 \%, 6.17 \%, 66.11 \%, 7.23 \%$ and $7.56 \%$, respectively. The grassland in SRLa, ESR, SR, IV, SD, ESD accounted for 26.55\%, 10.08\%, 51.43\%, $3.70 \%$ and $8.24 \%$, respectively. Grassland in SRYa had the maximum percentage of restoration, while grassland in SRYe had minimum percentages of degradation.

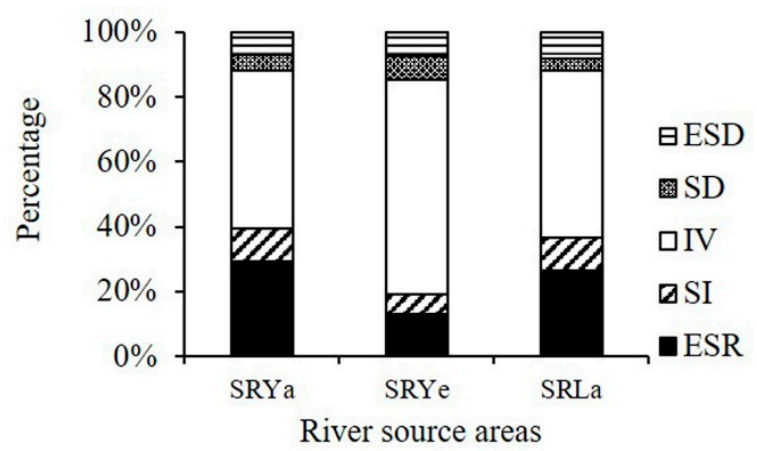

Figure 7. Area percentages of degradation in each river source region.

\section{Discussion}

The degeneration pattern of the TRSR grassland was formed in the 1970s, during which the herdsmen pursued immediate interest. The government also lacked an effective protective policy and management guidance plan, thus unreasonable human activities took place. For instance, overgrazing and reclamation aggravated the degradation of TRSR vegetation $[12,44]$. In view of this, the TRSR 
nature reserve was established in 2000 and promoted to status of the National Nature Reserve in 2003. The Three-River Source Region Nature Reserve Ecological Protection and Construction Project was approved in 2005, and a series of grassland ecological restoration measures, such as fencing, rodent control, "Black Beach" management, ecological migration, and ecological compensation, were implemented. Through manual visual interpretation of the two-phase TM image, $\mathrm{Xu}$ et al. [45] analyzed the grassland restoration situation of the TRSR in 2004-2012. They found that the grassland ecological environment improved obviously after the implementation of the TRSR ecological protection and construction project. The restoration of grassland distribution was good in the periphery of Eling and Zaling Lake, in the middle and north of Qumalai County, and in Chenduo County, whereas the degradation in Zhiduo County was serious. This result is consistent with the present findings. Community degradation is also a manifestation of grassland degradation, which is still difficult to achieve in large-scale remote sensing monitoring. Although vegetation productivity and coverage increased during the restoration of the TRSR, the community structure was not improved [46]. In addition, local climatic conditions have deteriorated over the last twelve years or so [27], and the grassland restoration and ecological protection project in the TRSR is yet to be realized.

Vegetation and soil degradation are different aspects of grassland degradation, and soil degradation is an essential manifestation of grassland degradation. Using vegetation indicators-such as biomass, coverage, or productivity-as diagnostic indicators of the health status of grassland ecosystems may result in the mistaking of natural vegetation growth for dynamic and grassland degradation, thereby complicating the process of soil degradation monitoring. In view of this, some studies have regarded the recuperability after a drought $[47,48]$ or precipitation utilization $[49,50]$ as land degradation diagnostic indicators. However, these indicators only consider precipitation, which is suitable for hot arid and semi-arid areas because of its absolute effect on vegetation growth. In the TRSR, the effect of precipitation on grassland is obviously less than that of radiation and temperature $[27,40]$. In particular, radiation plays a key role in vegetation growth [27]. This study suggests that CUE can manifest response and utilization efficiency of grass ecosystem with main climatic factors (light, temperature and water). It also has good robustness to inter-annual climatic fluctuation on grassland degradation monitoring. Therefore, it is more suitable to monitor the health status of grassland ecosystem in the alpine region. Even more, the CUE index plus local climate condition can partly reflect the degradation of grassland soil. In addition to the normal range of climatic fluctuations, extreme meteorological disasters, such as drought and low temperature, may cause a short period of damage to the grassland, resulting in grassland degradation. In this case, the fluctuation of the CUE value will have a certain lag (that is, the CUE value of the year may not be reduced, and the low value of the period after the climatic condition is restored). The vast grassland ecosystems that are at high altitudes or in high latitudes, temperature, radiation, and other climatic factors, significantly influence the growth of grassland vegetation. Compared with RUE, CUE can reduce the impact of climate fluctuation on ecosystem health evaluation. Thus, CUE is more suitable for remote sensing monitoring of grassland degradation/restoration in the Alpine region. In addition, in this study, the surface bareness index was introduced into the grassland ecological degradation of remote sensing evaluation system, achieving a good verification effect. Introduction of the index can improve utilization of remote sensing data on grassland resource monitoring and enrich evaluation indicators.

In recent years, research on grassland remote sensing monitoring has shown a developing tendency of data multi-scale, multi-source. The monitoring index has been transformed from a single index to comprehensive multiple indexes [5]. For example, Li et al. [51] found that the comprehensive evaluation index obtained from the weighted average of plant height, vegetation cover, and aboveground biomass is higher than that of the remote sensing vegetation index derived from Landset TM4/TM5. In addition, Zhou [52] assessed the grassland degradation pattern of China by the comprehensive index of NPP and grassland coverage. Our study used several remote sensing data products, introduced two indexes (CUE and bareness) into the large area of 
grassland degradation remote sensing monitoring, and constructed comprehensive evaluation factors of grassland degradation/restoration with two structural indexes (vegetation coverage and surface bareness) and two functional indexes (NPP and CUE). Taken together, the results of this study suggest that NPP, vegetation coverage, and surface bareness can be used to reflect the state of grassland ecosystems. Moreover, the introduction of CUE can reduce the influence of fluctuation of climatic factors (especially radiation and temperature). The bareness index, including surface reflectance and surface temperature properties, can also reflect soil degradation. The availability of remote sensing and meteorological data ensures the feasibility of this method for large-scale grassland ecosystem monitoring.

Grassland degradation can be defined as two categories, i.e., absolute and relative degradation, depending on degradation reference system [53]. The degeneration pattern of the TRSR grassland showed formation in the 1970s, and degradation in 2001. Therefore, our assessment of grassland degradation is not the absolute degradation of the natural grassland in ideal state but in the specific period and classification, according to the significant test. In the future, technological advancements such as free availability of satellite image in time series, online sharing of ecological data through crowd sourcing, and open access datasets will promote mapping and monitoring of grassland degradation across a range of scales. We should explore the diagnosis and monitoring of the absolute degree of grassland degradation in future works.

\section{Conclusions}

In this study, a simple remote sensing-based method to monitor grassland degradation was developed. CUE was proposed as a new index in monitoring grassland ecosystem function to mitigate the disturbance of climate fluctuation. EI, a comprehensive evaluation index, was established to monitor grassland degradation. Grassland degradation/restoration in the TRSR was evaluated quantitatively from 2001 to 2016. The vegetation coverage and CUE of the grassland showed upward trends, and their respective annual change rates were $0.75 \%$ and $0.45 \%$ year $^{-1}$. The surface bareness and NPP showed downward trends, with annual change rates of $-0.37 \%$ year ${ }^{-1}$ and $-0.24 \mathrm{~g} \mathrm{~cm}^{-2}$ year $^{-2}$, respectively. $67.18 \%$ of the grassland of TRSR showed a recovery trend. During the study period, the grassland of the SRYe had high vegetation coverage, NPP, and CUE and low degree of bareness, whereas the grassland of the SRYe had low vegetation cover, NPP, and CUE and high degree of bareness. The overall restoration of the SRYe was the best, followed by SRYa. Meanwhile, the status of SRLa was poor. We hope that our method will provide more comprehensive views of degradation remote sensing monitoring in grasslands at high altitudes or in high latitudes.

Author Contributions: Formal analysis, Y.Z.; funding acquisition, J.L., R.A.; software, Y.Z., Z.W., C.Z.; methodology, Y.Z., Z.W., C.Z.; writing-original draft, Y.Z.; writing-review \& editing, Y.Z., C.Z. All authors have approved the final article.

Funding: This research was funded by the "APN Global Change Fund Project" (No. ARCP2015-03CMY-Li \& CAF2015-RR14-NMY-Odeh), National Natural Science Foundation of China (No. 41271361), the National High Technology 863 Project of China (No. 2007AA10Z231), the National key R \& D project [No. 2018YFD0800201], The National Natural Science Foundation of China [No. 41501575], the Key Project of Chinese National Programs for Fundamental Research and Development [973 Program, No. 2010CB950702] and the Public Sector Linkages Program supported by the Australian Agency for International Development [PSLP: No. 64828].

Acknowledgments: We thank the management and staff of the Ecological Environment Remote Sensing Monitoring Center of Qinghai Province for their help during the field survey.

Conflicts of Interest: The authors declare no conflict of interest.

\section{References}

1. Gang, C.; Zhou, W.; Chen, Y.; Wang, Z.; Sun, Z.; Li, J.; Qi, J.; Odeh, I. Quantitative assessment of the contributions of climate change and human activities on global grassland degradation. Environ. Earth Sci. 2014, 72, 4273-4282. [CrossRef]

2. Le Houérou, H.N. Climate change, drought and desertification. J. Arid Environ. 1996, 34, 133-185. [CrossRef] 
3. The Ministry of Agriculture of the People's Republic of China. Grassland Resources of China; China Science and Technology Press: Beijing, China, 1996.

4. Nan, Z. The grassland farming system and sustainable agricultural development in China. Grassl. Sci. 2005, 51, 15-19. [CrossRef]

5. Dubovyk, O. The role of Remote Sensing in land degradation assessments: Opportunities and challenges. Eur. J. Remote Sens. 2017, 50, 601-613. [CrossRef]

6. Lawley, V.; Lewis, M.; Clarke, K.; Ostendorf, B. Site-based and remote sensing methods for monitoring indicators of vegetation condition: An Australian review. Ecol. Indic. 2016, 60, 1273-1283. [CrossRef]

7. Sarkar, S.; Kafatos, M. Interannual variability of vegetation over the Indian sub-continent and its relation to the different meteorological parameters. Remote Sens. Environ. 2004, 90, 268-280. [CrossRef]

8. Parplies, A.; Dubovyk, O.; Tewes, A.; Mund, J.-P.; Schellberg, J. Phenomapping of rangelands in South Africa using time series of RapidEye data. Int. J. Appl. Earth Obs. Geoinf. 2016, 53, 90-102. [CrossRef]

9. An, R.; Wang, H.-L.; Feng, X.-Z.; Wu, H.; Wang, Z.; Wang, Y.; Shen, X.-J.; Lu, C.-H.; Quaye-Ballard, J.A.; Chen, Y.-H.; et al. Monitoring rangeland degradation using a novel local NPP scaling based scheme over the "Three-River Headwaters" region, hinterland of the Qinghai-Tibetan Plateau. Quat. Int. 2017, 444, 97-114. [CrossRef]

10. Jackson, H.; Prince, S.D. Degradation of net primary production in a semiarid rangeland. Biogeosciences 2016, 13, 4721-4734. [CrossRef]

11. Karnieli, A.; Bayarjargal, Y.; Bayasgalan, M.; Mandakh, B.; Dugarjav, C.; Burgheimer, J.; Khudulmur, S.; Bazha, S.N.; Gunin, P.D. Do vegetation indices provide a reliable indication of vegetation degradation? A case study in the Mongolian pastures. Int. J. Remote Sens. 2013, 34, 6243-6262. [CrossRef]

12. Liu, J.; Xu, X.; Shao, Q. Grassland degradation in the "Three-River Headwaters" region, Qinghai Province. J. Geogr. Sci. 2008, 18, 259-273. [CrossRef]

13. Wang, Z.; Zhang, Y.; Yang, Y.; Zhou, W.; Gang, C.; Zhang, Y.; Li, J.; An, R.; Wang, K.; Odeh, I.; et al. Quantitative assess the driving forces on the grassland degradation in the Qinghai-Tibet Plateau, in China. Ecol. Inform. 2016, 33, 32-44. [CrossRef]

14. Liu, B.; You, G.; Li, R.; Shen, W.; Yue, Y.; Lin, N. Spectral characteristics of alpine grassland and their changes responding to grassland degradation on the Tibetan Plateau. Environ. Earth Sci. 2015, 74, 2115-2123. [CrossRef]

15. Yang, X.; Zhang, K.; Jia, B.; Ci, L. Desertification assessment in China: An overview. J. Arid Environ. 2005, 63, 517-531. [CrossRef]

16. Li, H.; Wei, X.; Zhou, H. Rain-use efficiency and NDVI-based assessment of karst ecosystem degradation or recovery: A case study in Guangxi, China. Environ. Earth Sci. 2015, 74, 977-984. [CrossRef]

17. Chang, J.; Tian, J.; Zhang, Z.; Chen, X.; Chen, Y.; Chen, S.; Duan, Z. Changes of Grassland Rain Use Efficiency and NDVI in Northwestern China from 1982 to 2013 and Its Response to Climate Change. Water 2018, 10, 1689. [CrossRef]

18. Del Barrio, G.; Sanjuan, M.E.; Hirche, A.; Yassin, M.; Ruiz, A.; Ouessar, M.; Martinez Valderrama, J.; Essifi, B.; Puigdefabregas, J. Land Degradation States and Trends in the Northwestern Maghreb Drylands, 1998-2008. Remote Sens. 2016, 8, 603. [CrossRef]

19. Zeng, Y.; Feng, Z. Advances in Sandy Desertification Detecting and Its Environmental Impacts. J. Mt. Res. 2005, 23, 218-227.

20. Foggin, J.M. Depopulating the Tibetan Grasslands: National Policies and Perspectives for the Future of Tibetan Herders in Qinghai Province, China. Mt. Res. Dev. 2008, 28, 26-31. [CrossRef]

21. Harris, R.B. Rangeland degradation on the Qinghai-Tibetan plateau: A review of the evidence of its magnitude and causes. J. Arid Environ. 2010, 74, 1-12. [CrossRef]

22. Fan, J.-W.; Shao, Q.-Q.; Liu, J.-Y.; Wang, J.-B.; Harris, W.; Chen, Z.-Q.; Zhong, H.-P.; Xu, X.-L.; Liu, R.-G. Assessment of effects of climate change and grazing activity on grassland yield in the Three Rivers Headwaters Region of Qinghai-Tibet Plateau, China. Environ. Monit. Assess. 2010, 170, 571-584. [CrossRef] [PubMed]

23. Hutchinson, M.F.; Dan, M.K.; Lawrence, K.; Pedlar, J.H.; Hopkinson, R.F.; Milewska, E.; Papadopol, P. Development and Testing of Canada-Wide Interpolated Spatial Models of Daily Minimum-Maximum Temperature and Precipitation for 1961-2003. J. Appl. Meteorol. Climatol. 2010, 48, 725-741. [CrossRef] 
24. FAO; IIASA; ISRIC; ISSCAS; JRC. Harmonized World Soil Database (Version 1.1); FAO: Rome, Italy; IIASA: Laxenburg, Austria, 2009; Available online: http://www.iiasa.ac.at/research/LUC/External-WorldSoil6database/HTML (accessed on 25 March 2019).

25. Mu, S.; Zhou, S.; Chen, Y.; Li, J.; Ju, W.; Odeh, I.O.A. Assessing the impact of restoration-induced land conversion and management alternatives on net primary productivity in Inner Mongolian grassland, China. Glob. Planet. Chang. 2013, 108, 29-41. [CrossRef]

26. Zhu, W.; Pan, Y.; Zhang, J. Estimation of net primary productivity of chinese terrestrial vegetation based on remote sensing. Chin. J. Plant Ecol. 2007, 31, 413-424.

27. Zhang, Y.; Zhang, C.; Wang, Z.; Chen, Y.; Gang, C.; An, R.; Li, J. Vegetation dynamics and its driving forces from climate change and human activities in the Three-River Source Region, China from 1982 to 2012. Sci. Total Environ. 2016, 563-564, 210-220. [CrossRef]

28. Yu, D.; Shi, P.; Shao, H.; Zhu, W.; Pan, Y. Modelling net primary productivity of terrestrial ecosystems in East Asia based on an improved CASA ecosystem model. Int. J. Remote Sens. 2009, 30, 4851-4866. [CrossRef]

29. Potter, C.S.; Randerson, J.T.; Field, C.B.; Matson, P.A.; Vitousek, P.M.; Mooney, H.A.; Klooster, S.A. Terrestrial ecosystem production: A process model based on global satellite and surface data. Glob. Biogeochem. Cycles 1993, 7, 811-841. [CrossRef]

30. Ruimy, A.; Kergoat, L.; Bondeau, A.; The Participants of the potsdam NPP model intercomparison. Comparing global models of terrestrial net primary productivity (NPP): Analysis of differences in light absorption and light-use efficiency. Glob. Chang. Biol. 1999, 5, 56-64. [CrossRef]

31. Saxton, K.E.; Rawls, W.J.; Romberger, J.S.; Papendick, R.I. Estimating Generalized Soil-water Characteristics from Texture. Soil Sci. Soc. Am. J. 1986, 50, 1031-1036. [CrossRef]

32. Gutman, G.; Ignatov, A. The derivation of the green vegetation fraction from NOAA/AVHRR data for use in numerical weather prediction models. Int. J. Remote Sens. 1998, 19, 1533-1543. [CrossRef]

33. Wang, Z.; Gang, C.; Li, X.; Chen, Y.; Li, J. Application of a normalized difference impervious index (NDII) to extract urban impervious surface features based on Landsat TM images. Int. J. Remote Sens. 2015, 36, 1055-1069. [CrossRef]

34. Wang, Z.; Li, J.; Yang, Y.; Li, H.; Wu, M.; Wang, K.; Shi, X.; Shi, W.; Xie, B. Quantitative Assess the Dynamic Change of Urban Ecological Environment Based on Remote Sensing-A Case Study in Yixing City, Jiangsu Province. J. Ningxia Univ. Sci. Ed. 2017, 38, 297-301.

35. Lambin, E.F.; Ehrlich, D. The surface temperature-vegetation index space for land cover and land-cover change analysis. Int. J. Remote Sens. 1996, 17, 463-487. [CrossRef]

36. Wei, M.; Lin, H.; Wang, Z. Study on the"Heat Island Effect" of Barren Patch on Degradation Sequences of Alpine Meadow in the Source Region of the Yangtze and Yellow River, Qinghai-Tibetan Plateau, China. Chin. J. Grassl. 2015, 32, 22-29.

37. Jin, H.; Ma, W.; Cheng, G.; Zhang, Y. Dual influences of local environmental variables on ground temperatures on the Qinghai-Tibet Plateau. In Proceedings of the AGU Fall Meeting, San Francisco, CA, USA, 15-19 December 2008; Volume 21, p. GC21A-0728.

38. Prince, S.D.; Wessels, K.J.; Tucker, C.J.; Nicholson, S.E. Desertification in the Sahel: A reinterpretation of a reinterpretation. Glob. Chang. Biol. 2007, 13, 1308-1313. [CrossRef]

39. Le Houérou, H.N.; Bingham, R.L.; Skerbek, W. Relationship between the variability of primary production and the variability of annual precipitation in world arid lands. J. Arid Environ. 1988, 15, 1-18. [CrossRef]

40. Chen, Q.; Zhou, Q.; Liu, F.; Zhang, H. Spatial disparity of NDVI response in vegetation growing season to climate change in the Three-River Headwaters Region. Ecol. Environ. Sci. 2010, 19, 1284-1289.

41. Zhou, W.; Yang, H.; Huang, L.; Chen, C.; Lin, X.; Hu, Z.; Li, J. Grassland degradation remote sensing monitoring and driving factors quantitative assessment in China from 1982 to 2010. Ecol. Indic. 2017, 83, 303-313. [CrossRef]

42. Khaledian, Y.; Kiani, F.; Ebrahimi, S.; Brevik, E.C.; Aitkenhead-Peterson, J. Assessment and Monitoring of Soil Degradation during Land Use Change Using Multivariate Analysis. Land Degrad. Dev. 2017, 28, 128-141. [CrossRef]

43. Wu, Y.; Tan, H.; Deng, Y.; Wu, J.; Xu, X.; Wang, Y.; Tang, Y.; Higashi, T.; Cui, X. Partitioning pattern of carbon flux in a Kobresia grassland on the Qinghai-Tibetan Plateau revealed by field 13C pulse-labeling: PARTITIONING PATTERN OF CARBON FLUX. Glob. Chang. Biol. 2009, 16, 2322-2333. [CrossRef] 
44. Fang, Y. Managing the Three-Rivers Headwater Region, China: From Ecological Engineering to Social Engineering. AMBIO 2013, 42, 566-576. [CrossRef] [PubMed]

45. Xu, X.; Wang, L.; Li, J.; Cai, H. Analysis of the Grassland Restoration Trend and Degradation Situation in the "Three-River Headwaters" Region since the Implementation of the Ecological Project. J. Geo-Inf. Sci. 2017, 19, 855-868.

46. Shao, Q.; Fan, J.; Liu, J. Assessment on the effects of the first-stage ecological conservation and restoration project in Sanjiangyuan region. Acta Geogr. Sin. 2013, 9, 1645-1656.

47. Tucker, C.J.; Dregne, H.E.; Newcomb, W.W. Expansion and Contraction of the Sahara Desert from 1980 to 1990. Science 1991, 253, 299-300. [CrossRef]

48. Hellden, U. Desertification-Time for an assessment? AMBIO 1991, 20, 372-383.

49. Nicholson, S.E.; Tucker, C.J.; Ba, M.B. Desertification, Drought, and Surface Vegetation: An Example from the West African Sahel. Bull. Am. Meteorol. Soc. 1998, 79, 815-829. [CrossRef]

50. Prince, S.D.; De Colstoun, E.B.; Kravitz, L.L. Evidence from rain-use efficiencies does not indicate extensive Sahelian desertification. Glob. Chang. Biol. 1998, 4, 359-374. [CrossRef]

51. Li, H.; Liu, S. Research on grassland degradation assessment model based on ETM+Image-A case study in Naqu County of Tibet. J. Desert Res. 2007, 27, 412-418.

52. Zhou, W.; Gang, C.; Zhou, L.; Chen, Y.; Li, J.; Ju, W.; Odeh, I. Dynamic of grassland vegetation degradation and its quantitative assessment in the northwest China. Acta Oecol. 2014, 55, 86-96. [CrossRef]

53. Yan, Y.; Tang, H. Differentiation of related concepts of grassland degradation. Acta Prataculturae Sin. 2008, 17, 93-99.

(C) 2019 by the authors. Licensee MDPI, Basel, Switzerland. This article is an open access article distributed under the terms and conditions of the Creative Commons Attribution (CC BY) license (http:/ / creativecommons.org/licenses/by/4.0/). 